\title{
Clinical features of hemodialysis patients treated for hepatocellular carcinoma: Comparison between resection and radiofrequency ablation
}

\author{
ATSUSHI HIRAOKA ${ }^{1}$, TAKASHI KUMADA ${ }^{2}$, KOJIRO MICHITAKA ${ }^{1}$, HIDENORI TOYODA $^{2}$, \\ TOSHIFUMI TADA ${ }^{2}, \mathrm{KOICHI} \mathrm{TAKAGUCHI}^{3}, \mathrm{KUNIHIKO} \mathrm{TSUI}^{4}$, EI ITOBAYASHI ${ }^{5}$, DAICHI TAKIZAWA ${ }^{6}$, \\ MASASHI HIROOKA ${ }^{7}$, YOHEI KOIZUMI ${ }^{7}$, HIRONORI OCHI ${ }^{8}$, KOJI JOKO ${ }^{8}$, YOSHIYASU KISAKA ${ }^{9}$, \\ YUKO SHIMIZU $^{10}$, KAZUTO TAJIRI $^{11}$, JOJI TANI ${ }^{12}$, TATSUYA TANIGUCHI ${ }^{13}$, AKIKO TOSHIMORI ${ }^{14}$ \\ and SHINICHI FUJIOKA ${ }^{15}$; On behalf of The Real-Life Practice Experts For Hepatocellular \\ Carcinoma (HCC) (RELPEC) Study Group and The HCC 48 Group (HCC experts from 48 clinics)
}

\footnotetext{
${ }^{1}$ Gastroenterology Center, Ehime Prefectural Central Hospital, Matsuyama, Ehime 790-0024;

${ }^{2}$ Department of Gastroenterology and Hepatology, Ogaki Municipal Hospital, Ogaki, Gifu 503-8502;
}

${ }^{3}$ Department of Hepatology, Kagawa Prefectural Central Hospital, Takamatsu, Kagawa 760-8557; ${ }^{4}$ Center of Gastroenterology, Teine Keijinkai Hospital, Sapporo, Hokkaido 006-8555; ${ }^{5}$ Department of Gastroenterology, Asahi General Hospital, Asahi, Chiba 289-2511; ${ }^{6}$ Department of Gastroenterology, Isesaki Municipal Hospital, Isezaki, Gunma 372-0817; ${ }^{7}$ Department of Gastroenterology and Metabolism, Ehime University Graduate School of Medicine, Toon, Ehime 791-0295;

${ }^{8}$ Center for Liver-Biliary-Pancreatic Diseases, Matsuyama Red Cross Hospital, Matsuyama, Ehime 790-8524; ${ }^{9}$ Department of Gastroenterology, Shiritsu Uwajima Hospital, Uwajima, Ehime 798-8510; ${ }^{10}$ Department of Gastroenterology,

Shiritsu Ozu Hospital, Ozu, Ehime 795-8501; ${ }^{11}$ Department of Gastroenterology, Toyama University Graduate School of Medicine, Toyama 930-0194; ${ }^{12}$ Department of Gastroenterology, Kagawa University Graduate School of Medicine, Kagawa 761-0793; ${ }^{13}$ Department of Gastroenterology, Tokushima University Graduate School of Medicine, Tokushima 770-8503; ${ }^{14}$ Department of Internal Medicine, Saiseikai Imabari Hospital, Imabari, Ehime 799-1592;

${ }^{15}$ Department of Gastroenterology, Okayama Saiseikai General Hospital, Okayama 750-8511, Japan

Received December 17, 2015; Accepted February 15, 2017

DOI: $10.3892 /$ mco.2017.1192

\begin{abstract}
There is no consensus regarding which therapeutic option is better and/or safer for treating hemodialysis (HD) patients with hepatocellular carcinoma (HCC). The present study compared surgical resection $(\mathrm{Hx})$ and radiofrequency ablation (RFA) with regard to therapeutic efficacy in HD patients with HCC. Of 108 HD patients with naïve HCC treated at 15 institutions between 1988 and 2014 enrolled in the present study, 58 fulfilled the up-to-7 criteria [7 as the sum of the size of the largest tumor $(\mathrm{cm})$ and the number of tumors] and were treated with Hx $(n=23)$ or RFA $(n=35)$; their clinical features, complications and prognosis were assessed. The frequency of hepatitis $\mathrm{C}$ virus was higher in the RFA group compared with
\end{abstract}

Correspondence to: Dr Atsushi Hiraoka, Gastroenterology Center, Ehime Prefectural Central Hospital, 83 Kasuga-Cho, Matsuyama, Ehime 790-0024, Japan

E-mail: hirage@m.ehime-u.ac.jp

Key words: hepatocellular carcinoma, hemodialysis, surgical resection, radiofrequency ablation, end-stage renal disease, prognosis that in the Hx group $(\mathrm{P}=0.002)$, whereas there were no differences between the groups with regard to the average time from the first HD ( $\mathrm{P}=0.953)$, tumor-nodes-metastasis (TNM) stage (Union for International Cancer Control 7th edition) $(\mathrm{P}=0.588)$, TNM stage (Liver Cancer Study Group of Japan 5th edition) $(\mathrm{P}=0.095)$, Child-Pugh classification $(\mathrm{P}=0.094)$, and Japan Integrated Scoring system $(\mathrm{P}=0.489)$. There were no significant differences in overall survival (OS) and disease-free survival (DFS) rates between the Hx and RFA groups [1-, 3- and 5-year OS rates: $81.7,55.6$ and $43.3 \%$ vs. $89.9,67.1$ and $56.3 \%$, respectively $(\mathrm{P}=0.454) ; 1$-, 3- and 5-year DFS rates: 71.1, 30.5 and $18.3 \%$ vs. $63.8,31.6$ and $21.1 \%$, respectively $(\mathrm{P}=0.911)$ Complications were observed in 4 patients $(11.4 \%)$ in the RFA group ( 2 with subcapsular hemorrhage, 1 with intraperitoneal bleeding and 1 with tardive intrahepatic hematoma) and in 4 patients $(17.4 \%)$ in the Hx group ( 2 with postoperative infection, 1 with liver failure and 1 with pleural effusion) $(\mathrm{P}=0.700)$. In conclusion, $\mathrm{Hx}$ and RFA have a similar therapeutic efficacy in HD patients with naïve HCC who fulfilled the up-to-7 criteria.

\section{Introduction}

Hepatocellular carcinoma (HCC) is the fifth most common cancer type in males, and the ninth most common in females (1). 
Although the number of hemodialysis (HD) patients with HCC remains low, the development of an effective therapeutic strategy for them is of clinical importance. It is well known that, as $\mathrm{HD}$ poses a risk for hepatitis $\mathrm{C}$ virus (HCV) infection, the $\mathrm{HCV}$-positive rate is increased in $\mathrm{HD}$ patients, while $\mathrm{HCV}$ is a major risk factor for HCC (2). Ozer Etik et al (3) reported that the prevalence of anti-HCV seropositivity among patients receiving maintenance HD in developed countries ranges from 5-60\% (3). However, the number of patients with diabetes mellitus (DM) has been increasing and diabetic nephropathy has become the primary reason for requiring HD (4). Furthermore, DM has recently been reported to be an independent risk factor for $\mathrm{HCC}(5)$, and thus it is expected that the number of HD patients with HCC will increase in the near future.

Hepatic resection $(\mathrm{Hx})$ is a good therapeutic option for HCC (6,7), while radiofrequency ablation (RFA) has become the standard low-invasive therapy for small $\operatorname{HCC}(8,9)$. However, there is no consensus regarding which therapeutic option is better and/or safer for HD patients with small HCC. The aim of the present study was to retrospectively analyze clinical features, complications and prognosis of HD patients with small HCC treated with Hx or RFA.

\section{Materials and methods}

A total of 108 HD patients with naïve HCC who were treated at one of our 15 institutions (Ehime Prefectural Central Hospital, Matsuyama; Ogaki Municipal Hospital, Ogaki; Kagawa Prefectural Central Hospital, Takamatsu; Teine Keijinkai Hospital, Sapporo; Asahi General Hospital, Asahi; Isesaki Municipal Hospital, Isesaki; Ehime University Hospital, Toon; Matsuyama Red Cross Hospital, Matsuyama; Shiritsu Uwajima Hospital, Uwajima; Shiritsu Ozu Hospital, Ozu; Toyama University Hospital, Toyama; Kagawa University Hospital, Kagawa; Tokushima University Hospital, Tokushima; Saiseikai Imabari Hospital, Imabari; Okayama Saiseikai General Hospital, Okayama, Japan) between January 1988 and December 2014 were enrolled in the present study. Of these, 58 fulfilled the up-to-7-criteria [7 as the sum of the size of the largest tumor (cm) and the number of tumors] $(10,11)$, and were treated with Hx (Hx group, $n=23$ ) or RFA (RFA group, $n=35$ ) as the curative therapy. Transcatheter arterial chemoembolization (TACE) was performed as the palliative treatment in 24 patients. All the patients had end-stage renal disease (ESRD), which requires HD or peritoneal dialysis. HCC patients within the up-to-7-criteria were regarded as having early-stage HCC. After receiving informed consent for curative treatment from each patient or their family, Hx or RFA was performed. The first HD session was performed 1 or 2 days after Hx or RFA with nafamostat mesylate (Torii Co., Ltd., Tokyo, Japan) instead of heparin.

Surveillance of HCC was mainly performed using ultrasonography (US), and diagnosis was based on an increasing course of $\alpha$-fetoprotein as well as findings obtained by dynamic computed tomography (12), magnetic resonance imaging and/or contrast-enhanced US (CEUS) with perflubutane (Sonazoid ${ }^{\circledR}$; Daiichi Sankyo Co., Ltd. Tokyo, Japan) (13). The tumor-nodes-metastasis (TNM) stage was determined according to the HCC staging systems of the Union for International Cancer Control, 7th edition (14) and the Liver Cancer Study Group of Japan (LCSGJ), 5th edition (15).
Child-Pugh classification (16) was used for evaluation of hepatic reserve function affected by liver cirrhosis. HBV and $\mathrm{HCV}$ positivity were determined based on positivity for the hepatitis B virus surface antigen ( $\mathrm{HBsAg}$ ) and $\mathrm{HCsAg}$, respectively.

RFA was performed from 2000 onwards as a curative therapy using previously reported methods (9). Selection of therapy (Hx or RFA) was independently determined by each institution. The physicians tended to select RFA when the size and number of tumors was small $(2.1 \pm 0.8 \mathrm{~cm}$ and $1.1 \pm 0.3$, respectively). When the patient or their family refused curative treatments, TACE was selected. For the TACE procedure, a microcatheter was inserted into the artery feeding the tumor in a super-selective manner after conventional hepatic angiography, followed by a segmental or subsegmental TACE procedure (17) performed by experienced radiologists and hepatologists. For embolization, epirubicin hydrochloride (Farmorubicin ${ }^{\circledR}$; Pfizer Japan Inc., Tokyo, Japan) was used throughout January 2010, while miriplatin hydrate (MIRIPLA $^{\circledR}$; Sumitomo Dainippon Pharma Co., Ltd., Osaka, Japan), was used from February 2010, which was injected together with lipiodol in all cases, after which a gelatin sponge cut into small fragments (Gelfoam ${ }^{\circledR}$; Upjohn, Kalamazoo, MI, USA) were used throughout August 2006, while small gelatin sponge fragments (Gelpart ${ }^{\circledR}$; Nippon Kayaku Co., Ltd., Tokyo, Japan) were used from September 2006.

The study protocol was approved by the Institutional Ethics Committee of Ehime Prefectural Central Hospital (Matsuyama, Japan; no. 26-11).

Statistical analysis. Data are expressed as the mean \pm standard deviation. Statistical analyses were performed using Welch's t-test for unpaired data, as well as Fischer's exact test, Mann-Whitney's U-test or a log-rank test with the Kaplan-Meyer method, as appropriate. All statistical analyses were performed using SPSS version 21 (IBM SPSS, Armonk, $\mathrm{NY}$, USA). $\mathrm{P}<0.05$ was considered to indicate a statistically significant difference.

\section{Results}

The average age of all the enrolled patients (91 males, 17 females) was $67.9 \pm 8.7$ years. The rate of $\mathrm{HCV}$-positivity, $\mathrm{HBV}$-positivity and $\mathrm{HBV}+\mathrm{HCV}$-positivity was $68.5,8.3$ and $2.8 \%$, respectively, while that of patients negative for $\mathrm{HCV}$ and $\mathrm{HBV}$ (nonBnonC) was $20.4 \%$. Among the nonBnonC patients with HCC, DM was the primary disease in $72.7 \%$ (16/22). The average time from the first HD was 4.6 \pm 4.8 years (range, $0.1-27$ years) (Table I). The frequency of patients within the up-to-7 criteria was $85.2 \%$ (92/108) and 64 of these underwent curative therapies; among them, 23 received $\mathrm{Hx}, 39$ received ablative therapy [RFA, 35; percutaneous ethanol injection therapy (PEIT), 2; microwave coagulation therapy (MCT), 2] and 2 received combination therapy with Hx and RFA (Fig. 1).

Comparison between patients within the up-to-7 criteria treated with Hx and those treated with RFA revealed no significant differences for most parameters, apart from the etiology of HCC $(\mathrm{P}=0.002)$, platelet count $(\mathrm{P}=0.013)$ and prothrombin time $(\mathrm{P}=0.042)$ (Table II). The overall survival $(\mathrm{OS})$ rate and disease-free survival (DFS) rate were not significantly 
Table I. Clinical features of HD patients with naïve HCC $(n=108)$.

Parameter/characteristic

Sex (male/female) (n)

Average age (years)

Etiology of HCC (HCV/HBV/HBV + HCV/nonBnonC) (n)

Performance status (0/1/2/3/4/unknown) (n)

Basal disease causing ESRD (n)

HD (machine/peritoneal) (n)

Average time from first HD, years (range)

Aspartate aminotransferase (IU/l)

Alanine aminotransferase (IU/l)

Platelets $\left(\mathrm{x} 10^{4}\right.$ cells $\left./ \mu \mathrm{l}\right)$

Total bilirubin $(\mathrm{mg} / \mathrm{dl})$

Albumin (g/dl)

Prothrombin time (\%)

Child-Pugh classification (A/B/C) (n)

Tumor size $(<2 / \geq 2 \mathrm{~cm}, \mathrm{n})$, (average, $\mathrm{cm}$ )

Number of tumors (single/multiple) (average)

Extrahepatic metastasis, n (\%)

Portal vein tumor thrombosis, n (\%)

Alpha-fetoprotein ( $\mathrm{ng} / \mathrm{ml})$

Des-gamma-carboxy prothrombin $(\mathrm{mUA} / \mathrm{ml})$

TNM stage (UICC 7th) I/II/III/IV (n)

TNM stage (LCSGJ 5th) I/II/III/IV (n)

Therapeutic method (Hx/RFA/Hx+RFA/MCT/PEIT/

TACE/RT/chemotherapy/BSC) (n)
Value

\section{$91: 17$}

$67.9 \pm 8.7$

$74: 9: 3: 22$

$54: 35: 4: 3: 12$

DM, 72; unknown, 26; nephrosclerosis, 3; chronic

glomerulonephritis, 3; renal stone, 1; multiple myeloma, 1;

IgA nephropathy, 1; rapidly progressive glomerulonephritis, 1

107:1

$4.6 \pm 4.8(0.1-27)$

$28.9 \pm 20.9$

$24.7 \pm 24.1$

$13.3 \pm 6.1$

$0.49 \pm 0.25$

$3.57 \pm 0.53$

$90.2 \pm 17.4$

89:19:0

$27: 81(3.24 \pm 2.27)$

$81: 27(1.45 \pm 1.06)$

2 (bone), (1.9\%)

$6(5.6 \%)$

$1,683.2 \pm 5,879.9$

$2,706.5 \pm 8,308.3$

$77: 22: 7: 2$

$25: 57: 21: 5$

$28: 35: 3: 2: 2: 29: 2: 1: 6$

Values are expressed as the mean \pm standard deviation. $\mathrm{HCC}$, hepatocellular carcinoma; HCV, hepatitis C virus; HBV, hepatitis B virus; nonBnonC, negative for HBV and HCV; ESRD, end-stage renal disease; DM, diabetes mellitus; IgA, immunoglobulin A; HD, hemodialysis; TNM, tumor-nodes-metastasis; UICC 7th, Union for International Cancer Control 7th edition; LCSGJ 5th, Liver Cancer Study Group of Japan 5th edition; RFA, radiofrequency ablation; Hx, surgical resection; MCT, microwave coagulation therapy; PEIT, percutaneous ethanol injection therapy; TACE, transcatheter arterial chemoembolization; RT, radiotherapy; BSC, best supportive care.

different between the Hx and RFA groups [1-, 3- and 5-year OS rates: $81.7,55.6$ and $43.3 \%$ vs. $89.9,67.1$ and $56.3 \%$, respectively; $\mathrm{P}=0.454$ (Fig. 2) and 1-, 3- and 5-year DFS rates: $71.1,30.5$ and $18.3 \%$ vs. $63.8,31.6$ and $21.1 \%$, respectively; $\mathrm{P}=0.911$ (Fig. 3)]. Post-procedure complications were observed in 4 of the 35 patients $(11.4 \%$ ) treated by RFA (subcapsular hemorrhage in the liver, 2; intraperitoneal bleeding, 1; tardive intrahepatic hematoma 4 days after RFA procedure, 1) and in 4 of the 23 patients $(17.4 \%)$ treated by $\mathrm{Hx}$ (post-operative infection, 2; liver failure, 1; pleural effusion, 1). No significant differences were identified in the frequencies of complications between the two groups $(\mathrm{P}=0.700)$. One patient died due to postoperative infection within 1 month in the $\mathrm{Hx}$ group, whereas no mortalities occurred in the RFA group $(\mathrm{P}=0.397$, according to Fischer's exact test).

In HCC patients who fulfilled the up-to-7-criteria, results of the Japan Integrated Scoring (JIS) system, calculated based on the Child-Pugh classification and TNM stage according to the LCSGJ classification, 5th edition (18) did not show any significant differences between patients treated with curative treatments

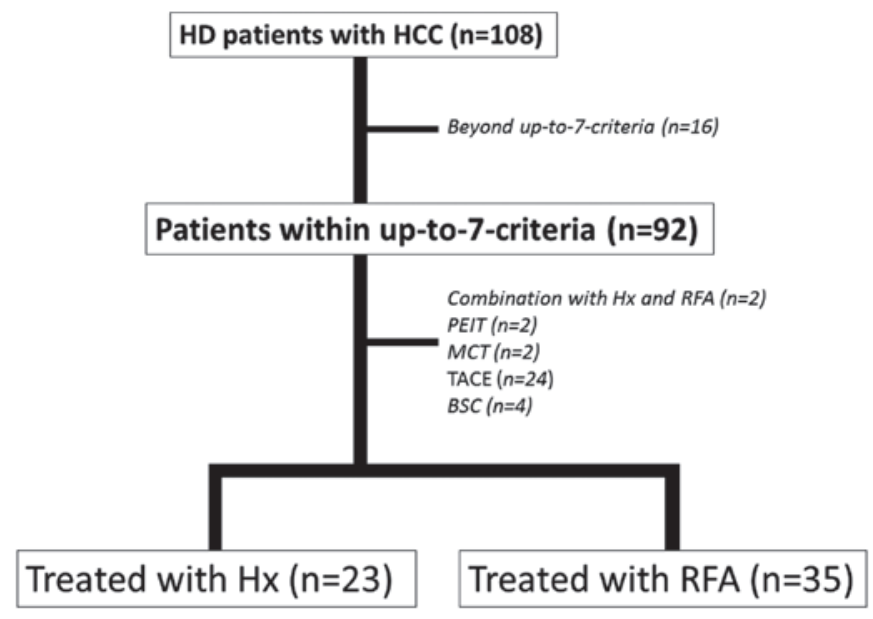

Figure 1. HD patients with naïve hepatocellular carcinoma. A total of 108 HD patients with naïve hepatocellular carcinoma were enrolled. Those within the up-to-7 criteria and treated with $\mathrm{Hx}$, RFA or transcatheter arterial chemoembolization were investigated. PEIT, percutaneous ethanol injection therapy; MCT, microwave coagulation therapy; BSC, best supportive care; $\mathrm{HD}$, hemodialysis; Hx, hepatic resection; RFA, radiofrequency ablation. 
Table II. Comparison of clinical features between Hx and RFA groups.

\begin{tabular}{|c|c|c|c|}
\hline Parameter/characteristic & $\mathrm{Hx}(\mathrm{n}=23)$ & RFA $(n=35)$ & P-value \\
\hline Sex ${ }^{\mathrm{a}}$ (male:female) (n) & $21: 2$ & $25: 10$ & 0.070 \\
\hline Average age ${ }^{\mathrm{b}}$ (years) & $68.4 \pm 9.1$ & $66.2 \pm 8.8$ & 0.359 \\
\hline $\begin{array}{l}\text { Etiology of } \mathrm{HCC}^{\mathrm{c}}(\mathrm{n}) \\
(\mathrm{HCV} / \mathrm{HBV} / \mathrm{HBV}+\mathrm{HCV} / \text { nonBnonC) }(\mathrm{n})\end{array}$ & $10: 4: 1: 8$ & $29: 2: 1: 3$ & 0.002 \\
\hline Performance status ${ }^{c}(0 / 1 / 2 / 3 / 4 /$ unknown$)$ & $11: 10: 1: 1: 0: 0$ & $16: 15: 0: 1: 0: 3$ & 0.387 \\
\hline Basal disease causing ESRD (n) & $\begin{array}{l}\text { DM, 15; IgA, 1; chronic } \\
\text { glomerulonephritis, } 1 ; \\
\text { nephrosclerosis, 1; } \\
\text { unknown, } 5\end{array}$ & $\begin{array}{c}\text { DM, 25; multiple } \\
\text { myeloma, 1; } \\
\text { nephrosclerosis, 1; } \\
\text { chronic } \\
\text { glomerulonephritis, 1; } \\
\text { unknown, } 7\end{array}$ & - \\
\hline HD (machine/peritoneal) (n) & $23: 0$ & $35: 0$ & - \\
\hline Average period after introducing $\mathrm{HD}^{\mathrm{b}}$ (years) & $5.3 \pm 5.7$ & $5.4 \pm 5.7$ & 0.953 \\
\hline Aspartate aminotransferase ${ }^{\mathrm{b}}(\mathrm{IU} / \mathrm{l})$ & $23.0 \pm 12.1$ & $34.4 \pm 30.7$ & 0.057 \\
\hline Alanine aminotransferase ${ }^{\mathrm{b}}(\mathrm{IU} / \mathrm{l})$ & $20.3 \pm 10.6$ & $30.4 \pm 35.2$ & 0.123 \\
\hline Platelets $^{\mathrm{b}}\left(\mathrm{x} 10^{4}\right.$ cells $\left./ \mu \mathrm{l}\right)$ & $15.1 \pm 6.3$ & $11.2 \pm 5.1$ & 0.013 \\
\hline Total bilirubin ${ }^{\mathrm{b}}$ (mg/dl) & $0.42 \pm 0.22$ & $0.56 \pm 0.27$ & 0.055 \\
\hline Albumin $^{\mathrm{b}}(\mathrm{g} / \mathrm{dl})$ & $3.76 \pm 0.51$ & $3.63 \pm 0.50$ & 0.350 \\
\hline Prothrombin time $\mathrm{e}^{\mathrm{b}}(\%)$ & $96.0 \pm 13.0$ & $87.4 \pm 16.7$ & 0.042 \\
\hline Child-Pugh classification $^{\mathrm{c}}(\mathrm{A} / \mathrm{B} / \mathrm{C})(\mathrm{n})$ & $22: 1: 0$ & 28:7:0 & 0.094 \\
\hline Tumor size $^{\mathrm{a}}(<2 / \geq 2 \mathrm{~cm}, \mathrm{n})$ (average, $\left.\mathrm{cm}\right)$ & $4: 19(2.8 \pm 1.0)$ & $14: 21(2.1 \pm 0.8)$ & 0.071 \\
\hline Tumor number ${ }^{\mathrm{a}}$ (single/multiple) & $20: 3(1.1 \pm 0.3)$ & $32: 3(1.1 \pm 0.3)$ & 0.612 \\
\hline Alpha-fetoprotein ${ }^{b}(\mathrm{ng} / \mathrm{ml})$ & $681.9 \pm 2,110.9$ & $831.5 \pm 4,147.0$ & 0.877 \\
\hline Des-gamma-carboxy prothrombin ${ }^{b}(\mathrm{mUA} / \mathrm{ml})$ & $2,035.4 \pm 6,265.8$ & $1,173.7 \pm 3,565.4$ & 0.522 \\
\hline TNM stage ${ }^{c}$ (UICC 7th) I/II/III/IV (n) & $20: 3: 0: 0$ & $32: 3: 0: 0$ & 0.588 \\
\hline TNM stage $^{c}$ (LCSGJ 5th) I/II/III/IV (n) & $3: 18: 2: 0$ & $13: 19: 3: 0$ & 0.095 \\
\hline JIS score ${ }^{c} 0 / 1 / 2 / 3(n)$ & $3: 17: 3: 0$ & $11: 17: 6: 1$ & 0.489 \\
\hline Complications $^{\mathrm{a}, \mathrm{d}}(\mathrm{n})$ & $\begin{array}{c}\text { Postoperative infection, } 2 \\
\text { (1 died within } 1 \text { month), } \\
\text { liver failure, } 1 ; \\
\text { pleural effusion, } 1^{\text {d }}\end{array}$ & $\begin{array}{l}\text { Intra-hepatic hematoma } \\
\text { after } 4 \text { days of RFA, } 1 \text {; } \\
\text { subcapsular hemorrhage } \\
\text { of liver, } 2 \text {; intraperitoneal } \\
\text { bleeding, } 1\end{array}$ & 0.700 \\
\hline Cause of mortality (n) & $\begin{array}{l}\text { HCC, } 2 \text {; infection, } 3 ; \\
\text { liver failure, } 2 \text {; acute } \\
\text { subdural hematoma, } 1 ; \\
\text { cardiac failure, } 1 ; \\
\text { arrhythmia, 1; } \\
\text { others/unknown, } 4\end{array}$ & $\begin{array}{c}\text { HCC, } 6 \text {; infection, } 1 ; \\
\text { liver failure, } 1 ; \\
\text { cerebral hemorrhage, } 2 \text {; } \\
\text { suffocation by accidental } \\
\text { ingestion, } 1 \text {; acute } \\
\text { respiratory distress } \\
\text { syndrome, } 1 \text {; general } \\
\text { prostration, } 1 ; \\
\text { others/unknown, } 2\end{array}$ & - \\
\hline
\end{tabular}

Values are expressed as the mean \pm standard deviation. Statistics were performed according to ${ }^{\mathrm{a}}$ Fischer's exact test; ${ }^{\mathrm{b}} \mathrm{Welch}$ 's $\mathrm{t}$-test; and ${ }^{\mathrm{c}}$ Mann-Whitney's U-test. ${ }^{\mathrm{d}}$ Complications arose in 4/23 (17.4\%) and 4/35 (11.4\%) of the patients in Hx and the RFA groups, respectively. RFA, radiofrequency ablation; $\mathrm{Hx}$, surgical resection; $\mathrm{HCC}$, hepatocellular carcinoma; $\mathrm{HCV}$, hepatitis $\mathrm{C}$ virus; $\mathrm{HBV}$, hepatitis B virus; nonBnonC, both negative for HBV and HCV; ESRD, end-stage renal disease; IgA, immunoglobulin A; DM, diabetes mellitus; HD, hemodialysis; TNM, tumor-nodes-metastasis; UICC, Union for International Cancer Control; LCSGJ, Liver Cancer Study Group of Japan; JIS system, Japan Integrated Scoring System.

(Hx or RFA, $\mathrm{n}=58$ ) and those who underwent palliative treatment (TACE, $\mathrm{n}=24)(\mathrm{P}=0.071)$. The OS rate for those who received curative treatments revealed a better prognosis compared with those who received TACE $(\mathrm{n}=24)$ [1-, 3- and 5-year OS rates: $90.6,62.3$ and $50.4 \%$ vs. $86.5,45.9$ and $0.0 \%$, respectively; $\mathrm{P}=0.010$, according to the log-rank test (data not shown)]. 


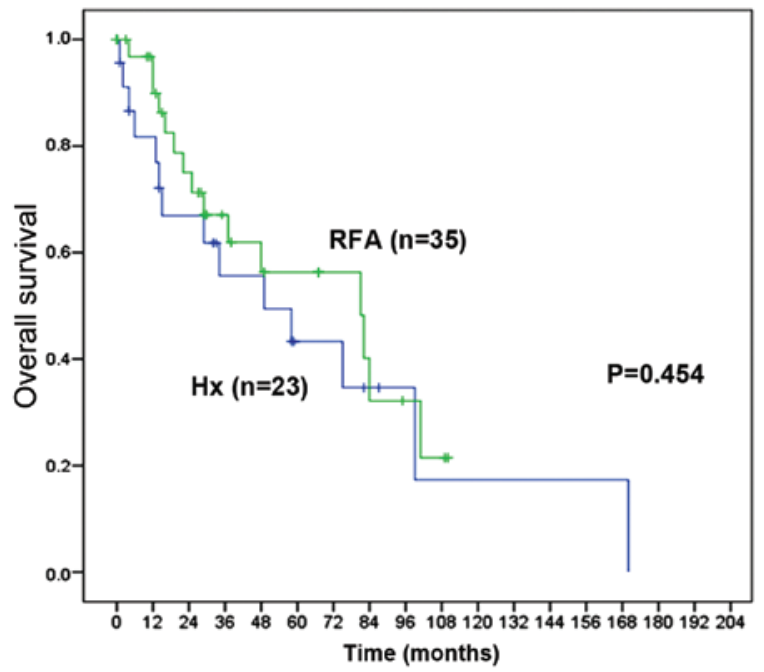

Figure 2. OSR for patients treated with hepatic resection or RFA. The overall survival rate for the Hx and RFA groups was not significantly different (1-, 3and 5-year OSR: $81.7,55.6$ and $43.3 \%$ vs. 89.9, 67.1 and $56.3 \%$, respectively; $\mathrm{P}=0.454)$. OSR, overall survival rate; RFA, radiofrequency ablation; $\mathrm{Hx}$, surgical resection.

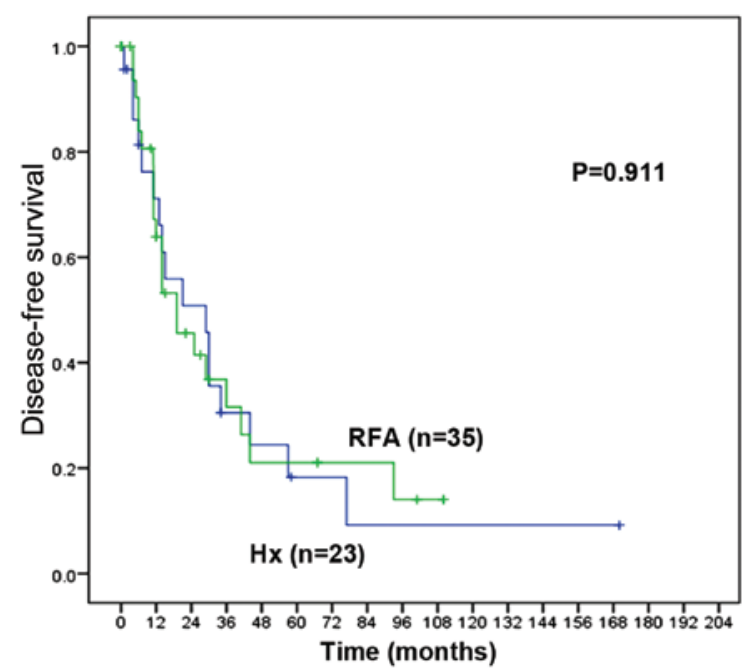

Figure 3. DFS for patients treated with Hx or RFA. The DFS rate was not significantly different between patients treated with $\mathrm{Hx}$ and RFA (1-, 3- and 5-year DFS rates: 71.1, 30.5 and $18.3 \%$ vs. 63.8, 31.6 and 21.1\%, respectively $\mathrm{P}=0.911$ ). DFS, disease-free survival. RFA, radiofrequency ablation; $\mathrm{Hx}$, surgical resection.

\section{Discussion}

Although the number of HD patients with HCC is low, such cases are at times encountered in the clinic. A previous study published in 1996 found that the frequency of HCV-positive HD patients was as high as $18.9 \%(409 / 2,164)$, while HCC was observed in only $2.4 \%$ (10/409) of HD patients with HCV infection (19). Factors associated with HCC in HCV-positive HD patients have remained elusive. However, positivity for DM was considered to have an important role for the occurrence of HCC in HD patients with $\mathrm{HCV}$ infection. In the present study, diabetic nephropathy was the most common primary disease leading to the requirement for $\mathrm{HD}$, while Henderson et al (20) noted that $\mathrm{HCC}$ was 1.3 times more likely to occur in HCV-positive HD patients with DM. Furthermore, the number of DM patients worldwide has been increasing recently. On the other hand, in patients without chronic viral hepatitis, DM increases the risk of chronic liver disease and HCC, with incidences of chronic non-alcoholic liver disease in patients with and without DM of 18.13 and 9.55 , respectively, per 10,000 individuals per year, and an incidence of HCC of 2.39 and 0.87 , respectively (21). Furthermore, that study found that DM is associated with an increased risk of chronic non-alcoholic liver disease and HCC [hazard ratio (HR), 1.98 and 2.16, respectively]. Noto et al (22) also reported that DM was associated with an increased risk for HCC (HR, 3.64; 95\% confidence interval, 2.61-5.07) in Japanese patients. DM and aging, particularly in patients with a high fibrosis-4 index, were found to be associated with an increased risk of HCC in a previous study by our group (23). In the present study, at least $72.7 \%$ (16/22) of the patients without viral hepatitis had DM. Cases of HCC among HD patients without chronic viral hepatitis infection may increase in the near future in association with the increase in patients with DM and diabetic nephropathy. In the present study, numerous HCC patients without viral hepatitis had DM and establishment of a surveillance strategy for $\mathrm{HCC}$ in HD patients with DM nephropathy is therefore required to detect $\mathrm{HCC}$ in as early a stage as possible. Furthermore, screening for HCC should also be performed in HD patients with chronic hepatitis, particularly those with HCV. Although interferon and ribavirin treatment is difficult in HD patients, the effectiveness and safety of HCV-NS5A-inhibitor (daclatasvir) and protease inhibitor (asunaprevir) combination therapy for HD patients with HCV has been reported recently $(24,25)$. Further progression in the development of direct-acting antiviral drugs will reduce the chronic hepatic diseases, HCV and HCC, in HD patients.

Although Hx and RFA are routinely performed as curative treatments for HCC, few studies have compared their efficacy and safety in HD patients. Generally, HX is performed as a curative treatment for HCC patients with good hepatic function $(6,26)$, while treatment with RFA is regarded as a curative local therapy for small HCC (27). Although Tung et al (28) reported that the prognosis of HD patients with HCC who were treated with $\mathrm{Hx}$ was not significantly different from that of those who received best supportive care, $\mathrm{Hx}$ has recently been established as an acceptable procedure for HD patients with HCC (29-32). In patients with good liver function and early-stage HCC (within up-to-7 criteria), curative treatments are expected to prolong survival. However, HD has been reported to be a risk factor in cases that undergo surgical resection due to a tendency to bleed arising from platelet dysfunction and heparin usage (33), susceptibility to infection (34) and impaired wound healing (35). In the present study, complications were observed in $17.4 \%$ (4/23) of patients in the Hx group (infection, 2; liver failure, 1; pleural effusion, 1), while complications occurred in $11.4 \%(4 / 35)$ of patients in the RFA group, each of which was based on bleeding (subcapsular hemorrhage in the liver, 2; intraperitoneal bleeding, 1; tardive intrahepatic hematoma, 1). However, no statistical difference in the complication rates was observed between the two groups $(\mathrm{P}=0.700)$. The characteristics of the patients who showed complications of bleeding could not be determined in the present cohort. The rate of complications associated with curative treatments in patients with HD is thought to be higher compared with that seen in those without 
HD. Few studies have noted that HCC patients with HD had a higher rate of complications compared with those without $\mathrm{HD}$, although the rates of post-operative infection after $\mathrm{Hx}$ (4.03 vs. $1.17 \% ; \mathrm{P}=0.0175)$ (31) and bleeding after RFA (13.3 vs. $0.79 \% ; \mathrm{P}=0.0002)(36)$ have been reported. When a curative treatment for HCC (Hx or RFA) is applied in a patient with HD, it is important to keep in mind that the risk of complications is greater compared with that in patients without HD; thus, detailed information must be given and informed consent must be obtained.

Although RFA has been gaining in importance in terms of prolonging the survival of HCC patients, particularly those with small tumors, there are few reports on RFA as a treatment for HCC in patients with HD (37). With increasing detection of small HCC due to the progression of imaging modalities [e.g., CEUS with Sonazoid (38)], the clinical significance of RFA in the treatment of small HCC for improving the prognosis of affected patients is expected to increase. In the present study, no significant differences in the OS and DFS rates were observed between the Hx and RFA groups, and no differences with regard to the JIS score were obtained (18). Lee et al (32) reported that, with regard to predicting the prognosis of HCC, the JIS score is a more accurate model for patients undergoing HD and is suitable for comparing the efficacy of therapies. The present study has demonstrated that the JIS scores and the therapeutic outcome were not different between the $\mathrm{Hx}$ and RFA groups, indicating equally important roles for the two modalities in HD patients with HCC.

In conclusion, the present study has determined that there were no significant differences between $\mathrm{Hx}$ and RFA with regard to the therapeutic outcome when applied for the treatment of HCC in HD patients within the up-to-7-criteria. As the present study was retrospective in nature and the number of patients was small, there were several limitations in terms of drawing firm conclusions. Accumulation of a greater number of cases and further analysis is therefore required.

\section{Acknowledgements}

The authors would like to thank Dr Kazuya Kariyama (Department of Gastroenterology, Okayama Shimin Hospital, Okayama), Dr Toru Ishikawa (Department of Gastroenterology, Saiseikai Niigata Daini Hospital, Niigata), Dr Shintaro Takagi (Department of Gastroenterology, Hiroshima Red Cross Hospital, Hiroshima), Dr Sung Kwan Bae (Department of Gastroenterology, Hamanomachi Hospital, Fukuoka), Dr Kazufumi Domen (Department of Gastroenterology, Chihaya Hospital, Fukuoka), Dr Chikara Ogawa (Department of Gastroenterology, Takamatsu Red Cross Hospital, Takamatsu), Dr Noritomo Shimada (Department of Gastroenterology, Ootakanomori Hospital, Kashiwa), Dr Akihiro Deguchi (Department of Gastroenterology, Kagawa Rosai Hospital, Marugame), Dr Ryoken Tanaka (Department of Gastroenterology, Matsuyama Shimin Hospital, Matsuyama), Dr Hiroaki Miyaoka (Department of Internal Medicine, Saiseikai Matsuyama Hospital, Matsuyama) and Dr Masamoto Torisu (Department of Internal Medicine, Saiseikai Saijo Hospital, Saijo) for their cooperation in searching the records of HD patients with HCC treated at their institutions.

\section{References}

1. GLOBOCAN 2012: Estimated Cancer Incidence, Mortality and Prevalence Worldwide in 2012. http://globocan.iarc. fr/Pages/fact_sheets_cancer.aspx. December 12, 2015.

2. Selcuk H, Kanbay M, Korkmaz M, Gur G, Akcay A, Arslan H, Ozdemir N, Yilmaz U and Boyacioglu S: Distribution of HCV genotypes in patients with end-stage renal disease according to type of dialysis treatment. Dig Dis Sci 51: 1420-1425, 2006.

3. Ozer Etik D, Ocal S and Boyacioglu AS: Hepatitis C infection in hemodialysis patients: A review. World J Hepatol 7: 885-895, 2015.

4. O'Toole SM, Fan SL, Yaqoob MM and Chowdhury TA: Managing diabetes in dialysis patients. Postgrad Med J 88: 160-166, 2012.

5. Renehen A, Smith U and Kirkman MS: Linking diabetes and cancer: A consensus on complexity. Lancet 375: 2201-2202, 2010.

6. Arii S, Yamaoka Y, Futagawa S, Inoue K, Kobayashi K, Kojiro M, Makuuchi M, Nakamura Y, Okita K and Yamada R: Results of surgical and nonsurgical treatment for small-sized hepatocellular carcinomas: A retrospective and nationwide survey in Japan. The Liver Cancer Study Group of Japan. Hepatology 32: 1224-1229, 2000.

7. Ikai I, Itai Y, Okita K, Omata M, Kojiro M, Kobayashi K, Nakanuma Y, Futagawa S, Makuuchi M and Yamaoka Y: Report of the 15th follow-up survey of primary liver cancer. Hepatol Res 28: 21-29, 2004

8. Shiina S, Teratani T, Obi S, Sato S, Tateishi R, Fujishima T, Ishikawa T, Koike Y, Yoshida H, Kawabe T and Omata M: A randomized controlled trial of radiofrequency ablation with ethanol injection for small hepatocellular carcinoma. Gastroenterology 129: 122-130, 2005.

9. Hiraoka A, Michitaka K, Horiike N, Hidaka S, Uehara T, Ichikawa S, Hasebe A, Miyamoto Y, Ninomiya T, Sogabe I, et al: Radiofrequency ablation therapy for hepatocellular carcinoma in elderly patients. J Gastroenterol Hepatol 25: 403-407, 2010.

10. Mazzaferro V, Llovet JM, Miceli R, Bhoori S, Schiavo M, Mariani L, Camerini T, Roayaie S, Schwartz ME, Grazi GL, et al: Predicting survival after liver transplantation in patients with hepatocellular carcinoma beyond the Milan criteria: A retrospective, exploratory analysis. Lancet Oncol 10: 35-43, 2009.

11. D'Amico F, Schwartz M, Vitale A, Tabrizian P, Roayaie S, Thung S, Guido M, del Rio Martin J, Schiano T and Cillo U: Predicting recurrence after liver transplantation in patients with hepatocellular carcinoma exceeding the up-to-seven criteria. Liver Transpl 15: 1278-1287, 2009.

12. Bruix J and Sherman M; Practice Guidelines Committee, American Association for the Study of Liver Diseases: Management of hepatocellular carcinoma. Hepatology 42: 1208-1236, 2005.

13. Hiraoka A, Hiasa Y, Onji M and Michitaka K: New contrast enhanced ultrasonography agent: Impact of Sonazoid on radiofrequency ablation. J Gastroenterol Hepatol 26: 616-618, 2011.

14. Sobin L, Gospodarowicz M and Wittekind C: TNM Classification of Malignant Tumors. 7th edition. John Wiley \& Sons, Inc., Hoboken, NJ, 2009.

15. Liver Cancer Study Group of Japan: General Rules for the Clinical and Pathological Study of Primary Liver Cancer. 5th edition. Kanehara \& Co., Ltd., Tokyo, p24, 2009.

16. Pugh RN, Murray-Lyon IM, Dawson JL, Pietroni MC and Williams R: Transection of the oesophagus for bleeding oesophageal varices. Br J Surg. 60: 646-649, 1973.

17. Matsui O, Kadoya M, Yoshikawa J, Gabata T, Takashima T and Demachi H: Subsegmental transcatheter arterial embolization for small hepatocellular carcinomas: Local therapeutic effect and 5-year survival rate. Cancer Chemother Pharmacol 33 (Suppl): S84-S88, 1994

18. Kudo M, Chung H and Osaki Y. Prognostic scoring system for hepatocellular carcinoma (CLIP score): Its value and limitations, and a proposal for a new staging system, the Japan Integrated Staging Score (JIS score). J Gastroenterol 38: 207-215, 2003.

19. Sakai Y, Izumi N, Tazawa J, Uchihara M, Akiba T, Marumo F and Sato C: Characteristics of anti-HCV antibody-positive patients with hepatocellular carcinoma on chronic hemodialysis: Recommendation of periodic ultrasonography for early detection. Nephron 74: 386-389, 1996.

20. Henderson WA, Shankar R, Gill JM, Kim KH, Ghany MG, Skanderson M and Butt AA: Hepatitis C progressing to hepatocellular carcinoma: The HCV dialysis patient in dilemma. J Viral Hepat 17: 59-64, 2010. 
21. El-Serag HB, Tran T and Everhart JE: Diabetes increases the risk of chronic liver disease and hepatocellular carcinoma. Gastroenterology 126: 460-468, 2004.

22. Noto H, Osame K, Sasazaki T and Noda M: Substantially increased risk of cancers in patients with diabetes mellitus: A systematic review and meta-analysis of epidemiologic evidence in Japan. J Diabetes Complications 24: 345-353, 2010.

23. Hiraoka A, Ochi M, Matsuda R, Aibiki T, Okudaira T, Kawamura T, Yamago H, Nakahara H, Suga Y, Azemoto N, et al: Ultrasonography screening for hepatocellular carcinoma in Japanese patients with diabetes mellitus. J Diabetes Sep 82015 (Epub ahead of print).

24. Suda G, Kudo M, Nagasaka A, Furuya K, Yamamoto Y, Kobayashi T, Shinada K, Tateyama M, Konno J, Tsukuda Y, et al: Efficacy and safety of daclatasvir and asunaprevir combination therapy in chronic hemodialysis patients with chronic hepatitis C. J Gastroenterol Jan 142016 (Epub ahead of print).

25. Toyoda H, Kumada T, Tada T, Takaguchi K, Ishikawa T, Tsuji K Zeniya M, Iio E and Tanaka Y: Safety and efficacy of dual direct-acting antiviral therapy (daclatasvir and asunaprevir) for chronic hepatitis $C$ virus genotype 1 infection in patients on hemodialysis. J Gastroenterol Feb 122016 (Epub ahead of print).

26. Ikai I, Arii S, Kojiro M, Ichida T, Makuuchi M, Matsuyama Y, Nakanuma Y, Okita K, Omata M, Takayasu K and Yamaoka Y: Reevaluation of prognostic factors for survival after liver resection in patients with hepatocellular carcinoma in a Japanese nationwide survey. Cancer 101: 796-802, 2004.

27. Hiraoka A, Horiike N, Yamashita Y, Koizumi Y, Doi K, Yamamoto Y, Hasebe A, Ichikawa S, Yano M, Miyamoto Y, et al: Efficacy of radiofrequency ablation therapy compared to surgical resection in 164 patients in Japan with single hepatocellular carcinoma smaller than $3 \mathrm{~cm}$, along with report of complications. Hepatogastroenterology 55: 2171-2174, 2008.

28. Tung CF, Yang DY, Hu WH, Peng YC, Chow WK and Chen GH: Characteristics of hepatocellular carcinoma in hemodialysis patients in hepatitis B endemic area. Hepatogastroenterology 50: $1564-1568,2003$
29. Yamagata M, Kanematsu T, Matsumata T, Nishizaki $T$, Utsunomiya T, Sugimachi $\mathrm{K}$ and Okuda S: Possibility of hepatic resection in patients on maintenance hemodialysis. Hepatogastroenterology 40: 249-252, 1993.

30. Orii T, Takayama T, Haga I, Fukumori T and Amada N: Efficacy of a liver resection for hepatocellular carcinoma in patients with chronic renal failure. Surg Today 38: 329-334, 2008.

31. Yeh CC, Lin JT, Jeng LB, et al: Hepatic resection for hepatocellular carcinoma patients on hemodialysis for uremia: A nationwide cohort study. World J Surg 37: 2402-2409, 2013

32. Lee YH, Hsu CY, Hsia CY, et al: Hepatocellular carcinoma in uremic patients: Is there evidence for an increased risk of mortality? J Gastroenterol Hepatol 28: 348-356, 2013

33. Kaw D and Malhotra D: Platelet dysfunction and end-stage renal disease. Semin Dial 19: 317-322, 2006.

34. Sarnak MJ and Jaber BL: Mortality caused by sepsis in patients with end-stage renal disease compared with the general population. Kidney Int 58: 1758-1764, 2000.

35. Ahonen $\mathrm{J}$ and Salmela K: Wound healing and infections in chronic renal failure. In: Surgery in Renal Failure. Eigler FW and Jakubowski HD (eds). George Thieme Verlag, New York, p68, 1984.

36. Minami Y, Hayaishi S and Kudo M: Radiofrequency ablation for hepatic malignancies: Is needle tract cauterization necessary for preventing iatrogenic bleeding? Dig Dis 31: 480-484, 2013

37. Kondo Y, Yoshida H, Tomizawa Y, Tateishi R, Shiina S, Tagawa $\mathrm{K}$ and Omata $\mathrm{M}$ : Percutaneous radiofrequency ablation of hepatocellular carcinoma in 14 patients undergoing regular hemodialysis for end-stage renal disease. AJR Am J Roentgenol 193: 964-969, 2009.

38. Hiraoka A, Ichiryu M, Tazuya N, Ochi H, Tanabe A, Nakahara H, Hidaka S, Uehara T, Ichikawa S, Hasebe A, et al: Clinical translation in the treatment of hepatocellular carcinoma following the introduction of contrast-enhanced ultrasonography with Sonazoid. Oncol Lett 1: 57-61, 2010 